\title{
Editorial
}

\section{Cold Stress at Work: Preventive Research}

Cold is a significant hazard in industrial work that is present outdoors as well as indoors. Outdoor work provides a seasonal exposure to cold that affects many countries at northern latitudes. Indoor cold environments often comprise the same climatic conditions throughout the year. Indoor exposures, for example in cold stores, occurs in all parts of the world.

Cold compromises the performance of work due to the required protective measures. Cooling of tissues causes discomfort, deterioration in performance and eventually in accidents and injuries. Much of the adverse effects of cold can be assessed by a relevant risk analysis and prevented by appropriate protective measures.

This issue of Industrial Health deals with Cold as a hazard in the work place. Internationally recognised scientists have provided reviews or original research papers on various aspects of cold work. The papers report on medical and physiological effects, on methods for assessment of cold stress and strain as well as on preventive actions to alleviate stress and reduce risks.

Mäkinen and Hassi ${ }^{1)}$ review the health problems related to cold work. A number of symptoms are reported that can be related to cold exposure. These are muscular skeletal complaints, respiratory distress and cardiovascular complaints. Also high lighted are susceptible groups such as people with diabetes, skin disorders and other diseases.

Repeated cooling of tissues under some conditions evoke physiological adjustments that counteract and reduce the cold strain. Different types of cold adaptation are reviewed by Launay and Savourey ${ }^{2}$. Most remarkable and pronounced adaptations have been found with primitive people in cold parts of the world. Cold exposure today is more controlled by technical means, but adaptation of extremities may still be a protective response in cold work.

Methods for assessment of cold exposure are readily available and reviewed by Holmér ${ }^{3)}$. Several international standards deal with various aspects of cold exposure. ISO $11079^{4)}$ covers methods for assessment of whole body cooling using the IREQ-index (required clothing insulation) as well as methods and procedures for evaluation of local cooling, such as extremity cooling, skin cooling and airways cooling. ISO $13732^{5)}$ provides information about risks associated with contacting cold surfaces with bare skin and their evaluation.
Much of the cold research work in Russia is not very well known outside the country. Afanasieva et al. ${ }^{6}$ ) describe their way of evaluating cold stress. Of particular interest is the division of the country in climate zones with defined requirements for protection.

Feet as well as hands are critical for performance in the cold. Kuklane ${ }^{7)}$ presents a comprehensive review of research, test methods and protection requirements.

Anttonen et $a l .{ }^{8)}$ have many years of experience with this kind of research and development work in Northern Finland. Their paper provides a pragmatic overview of preventive measures for alleviation of cold stress.

Deterioration in manual performance is critical in many work operations, in particular in cold operations. Daanen ${ }^{9)}$ discusses this problem and how its severity can be estimated using the new wind chill temperature.

Another study from Finland ${ }^{10)}$ reports about perceived symptoms in cold exposed workers in food industry. Some workers reported reduced work ability related to longer work duration and draught at the workplace. Perceived local cooling also correlated with musculoskeletal symptoms from the neck, shoulders, wrists and lower back.

Construction workers and traffic controllers are mostly working outdoors. Inaba et al. ${ }^{11)}$ report a higher frequency of shoulder and neck stiffness in traffic controllers and fatigue and lumbago in construction workers. Authors conclude that preventive measures are not sufficient for these workers to avoid risks of cold related disorders.

This initiative by the National Institute of Occupational Safety and Health (JNIOSH) has provided a good opportunity to review research on cold stress and its prevention in workplaces. This issue should serve as a valuable source of information for everyone interested in and working in the field.

\section{References}

1) Mäkinen $T$, Hassi $J$ (2009) Health problems in cold work. Industrial Health 47, 207-20.

2) Launay J-C, Savourey G (2009) Cold adaptations. Industrial Health 47, 221-7.

3) Holmér I (2009) Evaluation of cold workplaces —an overview of standards for assessment of cold stress. Industrial Health 47, 228-34. 
4) ISO-11079 (2007) Ergonomics of the thermal environment. Determination and interpretation of cold stress when using required clothing insulation (IREQ) and local cooling effects, 33, International Standards Organisation, Geneva.

5) ISO-13732/3 (2005) Ergonomics of the thermal environment -Assessment of human responses to contact with surfaces. Part 3 -Cold surfaces. International Standards Organisation, Geneva.

6) Afanasieva R, Bobrov A, Sokolov S (2009) Cold assessment criteria and prediction of cooling risk in humans. Industrial Health 47, 235-41.

7) Kuklane K (2009) Protection of feet in cold exposure. Industrial Health 47, 242-53.

8) Anttonen H, Pekkarinen A, Niskanen J (2009) Safety at work in cold environments and prevention of cold stress. Industrial Health 47, 254-61.

9) Daanen H (2009) Manual performance deterioration in the cold estimated using the wind-chill equivalent temperature. Industrial Health 47, 262-70.

10) Sormunen E, Remes J, Hassi J, Pienimäki T, Rintamäki H (2009) Factors Associated with self-estimated work ability and mussculoskeletal symptoms among male and female workers in cooled food-processing facilities. Industrial Health 47, 271-82.

11) Inaba R, Kurokawa J, Mirbod SM (2009) Comparison of subjective symptoms and cold prevention measures in winter between traffic control workers and construction workers in Japan. Industrial Health 47, 283-91.

\section{Editors of the Special Issue}

Ingvar HOLMÉR, $\mathrm{PhD}$

Ergonomics Department, Faculty of Engineering, Lund University, Sweden

Ken C. PARSONS, PhD

Department of Human Sciences, Loughborough University, UK

Yutaka TOCHIHARA, PhD

Department of Design Sciences, Kyushu University, Japan

Shin-ichi SAWADA, DrMedSc

National Institute of Occupational Safety and Health (JNIOSH), Japan 